\title{
The effects of poverty reduction policy on health services utilization among the rural poor: a quasi-experimental study in central and western rural China
}

\author{
Qi Zou, Xiaoqun He, Zhong Li, Wanchun Xu and Liang Zhang ${ }^{*}$ (D)
}

\begin{abstract}
Background: China poverty reduction policy (PRP) addresses two important elements: the targeted poverty reduction (TPA) project since 2015 in line with social assistance policy as national policy; and reducing inequality in health services utilization by making provision of medical financial assistance (MFA). Therefore, this study aims to assess the effects of the PRP in health services utilization (both inpatient and outpatient services) among the central and western rural poor of China.

Methods: The study conducted household survey and applied propensity score matching (PSM) method to assess the effects of the PRP on health services utilization among the rural poor of Central and Western China. A sensitivity test was also performed on the PSM results to test their robustness.

Results: Key findings showed $17.6 \%$ of respondents were the beneficial of PRP. The average treatment effects on the treated (ATT) of the PRP on the inpatient visits within one year was found significantly positive $(P=0.026)$.

Conclusion: There has been relationship between PRP with medical financial assistance and reduction of inequality in health services utilization by the poorer, in particular to accessing the inpatient services from the county or township hospitals of China. Policy makers should pay attention for making provision of improving responsiveness of supply, when subsidizing on the demand side.
\end{abstract}

Keywords: Poverty, Policy, Equality, Health services, Financial assistance, China

\section{Background}

China began its reform and opening up in 1978 as the economy continued to develop rapidly. Four decades of development have enabled China's economy to make remarkable achievements and considerably improve people's income and living standards [1, 2], resulting in the rapid decline in the number of rural poor from 250 million in 1978 to 30 million in 2017; the corresponding proportion of people living in poverty dropped from 30.7 to $3.1 \%$ [3]. The United Nations has proposed eliminating all forms of poverty in the world by 2030, as suggested in its sustainable development goals [2]. China's out-of-poverty population is

\footnotetext{
* Correspondence: zhanglianghust@126.com

School of Medicine and Health Management, Tongji Medical College, Huazhong University of Science and Technology, No 13 Hangkong Road, Qiaokou District, Wuhan 430030, Hubei, China
}

the largest in the world [4]; thus, it has made an outstanding contribution to the achievement of the sustainable development goals [4]. However, the number of rural poor in China is still very large. There were still 30 million rural people living below the poverty line in 2017 (annual per capita disposable income of less than $2300 \mathrm{RMB}$, which was approximately one dollar per day).

Several poverty reduction policy exist in rural China to help improve the living standards and socioeconomic status (SES) of the rural poor. The TPA project and social assistance are the two most important elements of China's PRP.

The TPA project was first proposed by President Xi Jinping in 2013 [5], and the central government made the decision to implement it in 2015 [6]. China's TPA aims to provide targeted assistance to rural residents living below the poverty line by eliminating factors that cause poverty

(c) The Author(s). 2019 Open Access This article is distributed under the terms of the Creative Commons Attribution 4.0 International License (http://creativecommons.org/licenses/by/4.0/), which permits unrestricted use, distribution, and reproduction in any medium, provided you give appropriate credit to the original author(s) and the source, provide a link to the Creative Commons license, and indicate if changes were made. The Creative Commons Public Domain Dedication waiver (http://creativecommons.org/publicdomain/zero/1.0/) applies to the data made available in this article, unless otherwise stated. 
[5]. China's TPA uses accurate measurement methods to identify poor households and individuals. The central and local governments help the poor emerge from poverty through strategies such as transfer payments, special industry development, employment projects and relocation for the rural poor [6]. In particular, in the field of health, the TPA has issued a special health poverty alleviation project aimed at providing rural poor people with equal access to health services through financial assistance [7].

Social assistance is another major PRP in China intended to guarantee the basic quality of life for the poor who cannot emerge from poverty through the TPA because they are unable to work, have no source of income or are elderly people and minors who are not supported by households. In 2014, the Chinese central government promulgated the Interim Measures for Social Assistance [8], which determined the current social assistance policy in the form of a national system. The minimum livelihood guarantee program (Dibao) and the poverty-stricken population support program (Wubao) are the main social assistance programs in China. Dibao is used to assist residents living below the minimum livelihood guarantee line and was first implemented in rural China in 2007 [9]. Wubao, which was first established in 2006 in the form of a government system for the rural extremely poor [10], aims to assist extremely vulnerable groups such as solitary people with no labor ability, widowed elderly people or unaccompanied children [10]. China's social assistance program uses various strategies to meet the basic needs of the poor, such as funding some living expenditures, supporting vulnerable groups and resettling affected people. In 2017, China's social assistance program covered approximately 45 million rural residents [3].

At present, the TPA plays a major role in poverty reduction in rural China [6]. The basic livelihood of households or individuals (especially extremely vulnerable groups) who are unable to escape poverty through industrial support or employment assistance is protected by social assistance supplements. China's PRP can effectively increase the income of the rural poor, considerably improve their living standards and assist the beneficiaries to emerge from poverty $[5,11,12]$.

Numerous reasons exist for rural Chinese residents to suffer from or return to poverty, such as disease, disasters, low education levels and unemployment. Among the different factors, disease is one of the main causes of poverty, affecting $42 \%$ of the poor population in China [13]. Lowincome groups tend to be less healthy than high-income groups owing to their weak SES [14]. Because low-income groups are more prone to illness, they are more likely to utilize health services; however, compared to high-income groups, they utilize such services less often [14-19]. This phenomenon means that the income gap hinders access to health services among the poor and that extensive inequality in health services utilization exists between lowincome and high-income groups.

The Chinese government launched the New Cooperative Medical Scheme (NCMS) in 2003 to reduce the health burden of rural residents and improve their access to health services. The scheme provides government cash subsidies and encourages voluntary participation among rural residents [20]. As of 2016, the NCMS covered $99.36 \%$ of all rural residents, achieving nearly full coverage [21]. The NCMS promotes registrants' health services utilization to a certain extent and reduces their health burden [22, 23]. However, the role of the NCMS in reducing the catastrophic health expenditures of rural residents is not obvious [2328]. Although the NCMS reduces the medical expenditures of high-income individuals, it does not effectively reduce the medical expenditures of low-income groups. Owing to this problem, the NCMS has played a limited role in reducing inequality in health services utilization [24, 25, 29].

China's PRP provides MFA to the beneficiaries to eliminate this inequality in health services utilization and to reduce the health burden of the rural poor. The MFA supplements the weaknesses of the NCMS in reducing inequality in health services utilization [30]. The beneficiaries of the PRP receive MFA in the following aspects: 1) insurance costs for the NCMS are all paid for by the government; 2) out-of-pocket (OOP) payments for serious disease treatments are subsidized; 3 ) medical rehabilitation programs for the disabled are integrated into the NCMS; 4) diagnosed serious diseases are treated before payment is made; and 5) the number of serious disease insurance deductible lines is reduced, and the proportion of insurance reimbursements for serious diseases is increased [7, 8]. In 2017, 56.21 million vulnerable individuals in China received government funding for basic medical insurance costs, and 35.151 million people received direct medical assistance. The expenditures on government-funded beneficiaries with basic medical insurance are approximately 7.4 billion yuan, and the direct medical assistance expenditures are approximately 26.61 billion yuan. Thus, the beneficiaries receive direct medical assistance of 756.6 yuan per capita [3].

In short, the beneficiaries of the PRP are financially assisted by the government and society and receive MFA when they are unable to afford expenditures after treatment. From this perspective, some of the goals and important initiatives of China's PRP to eradicate poverty include solving the problem of 'disease-induced poverty' among rural poor residents. The main goal of MFA is to reduce or eliminate the inequality in health services utilization caused by gaps in SES.

A previous quasi-experimental study found that TPA reduced out-of-pocket payments by $15 \%$ on average; decreased the probability of incurring catastrophic health expenditures and impoverishing health expenditures by 7.7 and $11.7 \%$, respectively, at the household level; and within one year 
increased the inpatient visit rate of impoverished households by 0.035 [31]. However, the study did not indicate the impact of the PRP on the beneficiaries' health services-seeking behavior at the individual level, and the role of the PRP in outpatient services utilization is still not clear. In addition to the above study, although other empirical studies have demonstrated that the PRP improves access to health services among the poor, unobserved variables (or hidden bias) cannot be eliminated because very few studies have applied rigorous randomized controlled trials (RCTs) or quasiexperimental methods for empirical analysis; thus, the evidence for their results and conclusions is not strong [32, 33].

\section{Method}

\section{Study design}

The study, which was based on a cross-section of residential health needs, aimed to evaluate the health services needs and utilization of Chinese residents. This study was conducted in two rural counties in China, namely, Dangyang and Sinan. Dangyang is a nonpoor county in Yichang City, Hubei Province, Central China, and Sinan is an impoverished county in Tongren City, Guizhou Province, Western China. A multistage stratified random sample was conducted for one-to-one interviews. Our sample for the household survey was 1355 households comprising 3983 individuals from 30 villages in Sinan and 1360 households comprising 3310 individuals from 30 villages in Dangyang.

This study used propensity score matching (PSM) to assess the effects of the PRP on the beneficiaries' health services utilization, including outpatient and inpatient services utilization, to fill the gaps in the research methods and content in this area and provide strong evidence for how the PRP improves medical assistance.

\section{Data collection}

We conducted a household survey in Sinan in July 2018 and in Dangyang in August 2018. Data were collected from a household-individual cross-sectional questionnaire that asked respondents about the background characteristics of their household as well as individual demographics, health status, health behaviors, health services needs and utilization and chronic disease management. We included individuals aged 15 years and older in this study. After individuals who did not match the selection criteria were excluded, our sample consisted of 6091 individuals.

\section{Dependent variables}

As shown in Table 1, we used the characteristics of health services utilization as dependent variables. The two variables selected as indicators of the outpatient services utilization characteristics of respondents who suffered from a disease within two weeks of the survey were the twoweek outpatient visit rate and the choice of outpatient institution. The two variables selected as indicators of inpatient services utilization characteristics were the inpatient visit rate within one year and the choice of inpatient institution. We defined the two-week outpatient visit rate as the ratio of the number of cases with outpatient visit to the number of cases with any disease within two weeks. We defined the inpatient visit rate within one year as the ratio of the number of inpatient who incurred at least one hospitalization to the total number of respondents within one year.

\section{Control variables}

The control variables used to assess the propensity scores are shown in Table 1. The household-level variables included distance between residence and the nearest health services institution and annual household income per capita. The variables at the individual level included gender, age, marital status, educational level and the utility index of the health-related quality of life (HRQoL). Moreover, we included clinical characteristic-related variables to the matching models to improve their accuracy in terms of choices of health services institutions. The types of diseases were classified as clinical characteristics related to the control variables. Among the control variables, we classified the respondents into 5 groups based on their annual household income per capita, namely, low-income group, lower-income group, middle-income group, higher-income group and highestincome group. We used the EQ-5D-3 L version of the 5th China National Health services Survey to measure the utility index of the HRQoL, which was applied to those who were 15 years old and older [34]. The EQ-5D-3 L method was used to calculate the time trade-off value to calculate the utility index of the HRQoL, and the evaluation method was revised by Professor Liu et al. according to the health status of Chinese residents, decreasing the gap between the utility index and their HRQoL [35]. We used the ICD-10, which was proposed by the $\mathrm{WHO}$, to classify the disease types of the two-week outpatients and one-year inpatients [36]. The distribution of disease types among the beneficiaries and nonbeneficiaries is shown in Table 5 of the Appendix.

\section{Statistical analysis}

We included the household- and individual-level information of all of the respondents in the data analysis. We used the likelihood chi-square test for the categorical variables and two independent sample t-tests or nonparametric tests for the continuous variables to compare the differences in health services utilization and background characteristics between the beneficiaries and nonbeneficiaries. Then, PSM was used to assess the ATT of the PRP on rural residents' health services utilization. First, we used the propensity score to find cases of nonbeneficiaries that are as similar as possible to those of beneficiaries. These cases constituted the 'control group', whereas the sample of beneficiaries included in the matching models was the 'treatment group'. The pretreatment characteristics of the 
Table 1 Health services utilization and background characteristics

\begin{tabular}{|c|c|c|c|c|}
\hline Variables, $\mathrm{n}(\%)$ or mean (SD) & $\begin{array}{l}\text { Total } \\
(n=6091)\end{array}$ & $\begin{array}{l}\text { Beneficiaries } \\
(n=1069)\end{array}$ & $\begin{array}{l}\text { Non-beneficiaries } \\
(n=5022)\end{array}$ & $P$-value \\
\hline \multicolumn{5}{|l|}{ Dependent variables outpatient services utilization within two weeks } \\
\hline Any outpatient visit & & & & 0.054 \\
\hline Yes & $461(18.84)$ & $96(22.12)$ & $365(18.13)$ & \\
\hline No & $1986(81.16)$ & $338(77.88)$ & $1648(81.87)$ & \\
\hline Outpatient institutions & & & & 0.310 \\
\hline Village clinic & $214(44.12)$ & $35(33.65)$ & $179(46.98)$ & \\
\hline Town health center & $99(20.41)$ & $27(25.96)$ & $72(18.90)$ & \\
\hline Public hospital above county-level & $142(29.28)$ & $38(36.54)$ & $104(27.30)$ & \\
\hline Private hospital or clinic & $30(6.19)$ & $4(3.85)$ & $26(6.82)$ & \\
\hline \multicolumn{5}{|l|}{ Inpatient services utilization of patients within one year } \\
\hline Any inpatient visit & & & & $<0.001$ \\
\hline Yes & $1188(19.50)$ & $276(25.82)$ & $912(18.16)$ & \\
\hline No & $4903(80.50)$ & $793(74.18)$ & $4110(81.84)$ & \\
\hline Inpatient institutions & & & & 0.274 \\
\hline Town health center & $351(27.04)$ & $83(27.76)$ & $268(26.83)$ & \\
\hline Public hospital of county-level & $742(57.16)$ & $179(59.87)$ & $563(56.36)$ & \\
\hline Public hospital above city-level & $164(12.63)$ & $28(9.36)$ & $136(13.61)$ & \\
\hline Private hospital or other institutions & $41(3.16)$ & $9(3.01)$ & $32(3.20)$ & \\
\hline \multicolumn{5}{|l|}{ Control variables } \\
\hline Area & & & & $<0.001$ \\
\hline Sinan County & $3090(50.73)$ & $754(70.53)$ & $2336(46.52)$ & \\
\hline Dangyang County & $3001(49.27)$ & $315(29.47)$ & $2686(53.48)$ & \\
\hline Distance between residence and nearest health services institutions $(\mathrm{km})$ & & & & $<0.001$ \\
\hline$\leq 1$ & $3037(49.90)$ & $503(47.14)$ & 2534(50.49) & \\
\hline $1 \sim 2$ & $1913(31.43)$ & 292(27.37) & $1621(32.30)$ & \\
\hline $2 \sim 3$ & $743(12.21)$ & 182(17.06) & $561(11.18)$ & \\
\hline $3 \sim 4$ & $158(2.60)$ & 25(2.34) & 133(2.65) & \\
\hline$>4$ & $235(3.86)$ & $65(6.09)$ & 170(3.39) & \\
\hline Household per capita annual income level & & & & $<0.001$ \\
\hline Low income group & $1218(20.00)$ & $368(34.42)$ & $850(16.93)$ & \\
\hline Lower income group & $1219(20.01)$ & $243(22.73)$ & $976(19.43)$ & \\
\hline Middle income group & $1210(19.87)$ & 193 (18.05) & $1017(20.25)$ & \\
\hline Higher income group & $1226(20.13)$ & $152(14.22)$ & $1074(21.39)$ & \\
\hline Highest income group & $1218(20.00)$ & $113(10.57)$ & $1105(22.00)$ & \\
\hline Gender & & & & 0.424 \\
\hline Male & $2992(49.17)$ & $537(50.28)$ & $2455(48.93)$ & \\
\hline Female & $3093(50.83)$ & $531(49.72)$ & $2562(51.07)$ & \\
\hline Age group & & & & $<0.001$ \\
\hline $15 \sim 24$ & $489(8.03)$ & $107(10.01)$ & $382(7.61)$ & \\
\hline $25 \sim 44$ & $1070(17.57)$ & $164(15.34)$ & $906(18.04)$ & \\
\hline $45 \sim 64$ & $2856(46.89)$ & $454(42.47)$ & $2402(47.83)$ & \\
\hline$\geq 65$ & $1676(27.52)$ & $344(32.18)$ & $1332(26.52)$ & \\
\hline
\end{tabular}


Table 1 Health services utilization and background characteristics (Continued)

\begin{tabular}{|c|c|c|c|c|}
\hline Variables, n (\%) or mean (SD) & $\begin{array}{l}\text { Total } \\
(n=6091)\end{array}$ & $\begin{array}{l}\text { Beneficiaries } \\
(n=1069)\end{array}$ & $\begin{array}{l}\text { Non-beneficiaries } \\
(n=5022)\end{array}$ & $P$-value \\
\hline Marital status & & & & $<0.001$ \\
\hline Unmarried & $601(9.91)$ & 156(14.70) & $445(8.89)$ & \\
\hline Married & $4851(79.98)$ & $768(72.38)$ & 4083(81.59) & \\
\hline Divorced & $54(0.89)$ & $15(1.41)$ & $39(0.78)$ & \\
\hline Widowed & $548(9.04)$ & 116(10.93) & $432(8.63)$ & \\
\hline Other & $11(0.18)$ & $6(0.57)$ & $5(0.10)$ & \\
\hline Education & & & & $<0.001$ \\
\hline Illiteracy & $1062(17.48)$ & 253(23.73) & $809(16.14)$ & \\
\hline Elementary school or junior high school & $4038(66.45)$ & $691(64.82)$ & $3347(66.79)$ & \\
\hline High school or secondary vocational and technical school & $803(13.21)$ & $90(8.44)$ & $713(14.23)$ & \\
\hline University degree & $174(2.86)$ & $32(3.00)$ & $142(2.83)$ & \\
\hline Severity of disease within two weeks & & & & $<0.001$ \\
\hline Not at all serious & $30(1.22)$ & $4(0.92)$ & $26(1.29)$ & \\
\hline Not too serious & $386(15.74)$ & $47(10.83)$ & $339(16.84)$ & \\
\hline Generally serious & $934(38.08)$ & $125(28.80)$ & $809(40.19)$ & \\
\hline Relatively serious & $989(40.32)$ & $223(51.38)$ & $760(37.75)$ & \\
\hline Very serious & $114(4.65)$ & $35(8.06)$ & 79 (3.92) & \\
\hline The utility index of HRQoL & $0.854(0.002)$ & $0.793(0.006)$ & $0.866(0.002)$ & $<0.001$ \\
\hline
\end{tabular}

Note: In the statistical analysis of dependent variables, for the variable 'any inpatient visit', we used an individual as an observation case. For other dependent variables, we used an outpatient or inpatient record as an observation case

treatment group and the control group were as similar to one another as possible. The variation in the control variables was derived from the treatment effects by controlling the pretreatment characteristics. We assessed the propensity scores by employing logistic regression $[37,38]$.

We chose the one-to-one neighbor matching method with replacements to select the treatment group and control group cases. We selected the two cases in the treatment and control groups with the closest match of propensity scores. The $95 \%$ confidence intervals were estimated by a bootstrap method. We used a balance test to estimate the bias before and after matching. Subsequently, we calculated the ATT of the PRP on beneficiaries' health services utilization and its significance in evaluating policy effectiveness. Finally, we used the Rosenbaum method to conduct a sensitivity analysis to determine the existence of unobserved variables that can affect rural residents' access to PRP coverage and health services utilization [39].

We used the Epidata software version 3.1 to perform double entry on the questionnaire data and to verify the entry results. The data were initially processed by MS Excel 2016 and analyzed by Stata software v.12 SE.

\section{Results}

Health services utilization and background characteristics Table 1 shows the health services utilization and background characteristics of the beneficiaries and nonbeneficiaries of the PRP. Overall, the proportion of Chinese rural residents receiving PRP benefits was 17.55\% $(1069 / 6091)$, the two-week outpatient visit rate was $18.84 \%$ (461/2447), and the inpatient visit rate within one year was $19.50 \%(1188 / 6091)$.

Specifically, the two-week outpatient visit rate $(22.12 \%)$ and inpatient visit rate within one year $(25.82 \%)$ were higher for the beneficiaries than for the nonbeneficiaries (18.13 and $18.16 \%)$. However, there was no significant difference in the choices of health services institutions between the two groups. Of the beneficiaries, $87.63 \%$ chose public hospitals at the county or township level to obtain inpatient services, and $59.61 \%$ chose village clinics or town health centers to obtain outpatient services. In terms of background characteristics, $6.09 \%$ of the beneficiaries were more than $4 \mathrm{~km}$ from the nearest health services institutions, compared to $3.39 \%$ of the nonbeneficiaries. The per capita annual income of $57.16 \%$ of the beneficiaries was below the middle income level, compared to $36.36 \%$ of the nonbeneficiaries. Of the beneficiaries, $32.18 \%$ were aged 65 and older, compared to $26.52 \%$ of the nonbeneficiaries. Regarding marital status, $72.38 \%$ of the beneficiaries were married, compared to $81.59 \%$ of the nonbeneficiaries. Regarding educational status, $23.73 \%$ of the beneficiaries were illiterate, compared to $16.14 \%$ of the nonbeneficiaries. Of the beneficiaries who were sick within two weeks, $8.06 \%$ felt that their disease was very serious, compared to $3.92 \%$ of the 
nonbeneficiaries (3.92\%). The average utility index of the HRQoL for the beneficiaries was $0.793 \pm 0.006$, compared to $0.866 \pm 0.002$ for the nonbeneficiaries.

\section{The quality of the PSM models}

Table 2 shows the quality of the matching models before and after the best matching sample. We determined the final analytical model based on the matching quality, which was evaluated based on the resulting quality parameters, including the mean and median absolute bias of variables, the pseudo- $R^{2}$ and the standard likelihood ratio test $\chi^{2}$. The results showed that the mean and median bias of the treatment and control variable sets of all the models were significantly reduced. Most of the observed variables in the two groups had a mean bias that was less than or close to $5 \%$. The pseudo- $\mathrm{R}^{2}$ was derived from the regression of the propensity scores of the variables of the matched and unmatched samples. If the quality of the propensity score match was good, then the matched pseudo- $R^{2}$ was significantly reduced $[37,38]$. The pseudo- $R^{2}$ was significantly reduced in all of our PSM models after they were matched. The variables' likelihood-ratio test of joint nonsignificance was nonsignificant, indicating that the distribution of all the variables in the two groups was similar after matching.

\section{The ATT of the PRP on health services utilization The ATT of the PRP on outpatient services utilization}

Table 3 shows the ATT of the PRP on health services utilization. There were no significant effects of the PRP on the two-week outpatient visit rate for rural residents $(P=0.976)$. Similarly, the PRP had no significant effects on rural residents' choices of the level of outpatient institutions $(P=0.945)$.

\section{The ATT of the PRP on inpatient services utilization}

During 2017, the ATT of the PRP for the inpatient visit rate within one year was 0.0515 and significant $(p<0.05)$. The results showed that the PRP had increased the inpatient visit rate within one year by approximately 5 percentage points. Meanwhile, the ATT of the PRP on rural residents' choices of outpatient institutions $(P=0.961)$.

\section{Sensitivity analysis for hidden bias}

The ATT obtained using PSM was based on the assumption that no influence of unobserved variables existed. However, a hidden bias may occur, and the matching results may no longer be robust if unobserved variables exist that can affect the access of the poor to PRP coverage and health services utilization [39]. Here, we used the sensitivity parameter gamma coefficient $(\Gamma)$, which was proposed by Rosenbaum, to measure the existence of a hidden bias in the model. If the background characteristics of the treatment and control groups were consistent, then $\Gamma$ was calculated based on the ratio of the treatment effects of the unobserved variables to the treatment group sample and the treatment effects of the control sample [39].

The basic principle of the Rosenbaum method is to use $\Gamma$ to measure the effects of the hidden bias on the processing estimates. If $\Gamma=1$, then the matching model has no hidden bias, and the outcomes are very robust. As $\Gamma$ increases, the level of the hidden bias increases simultaneously. Given that the unobserved variables cannot be measured, the $\Gamma$ value can likewise not be directly calculated; thus, the $\Gamma$ value is determined based on its value before the significance of the estimated treatment effects changes. The assumed maximum $\Gamma$ value is called the 'Rosenbaum boundary'. In the current study, the criteria for the $\Gamma$ value were not defined; however, in the social sciences, the $\Gamma$ value is usually limited between 1 and 2 to indicate that a hidden bias does not exist [40].

Table 4 shows the results of the sensitivity analysis of the matching models. For all of the matching models, $\Gamma=1$, showing that the processing effects were not sensitive to hidden bias, and no unobserved variables existed that would affect the access of the poor to the PRP.

\section{Discussion}

We used a quasi-experimental method to assess the effects of China's PRP on health services utilization and

Table 2 The quality of the PSM models

\begin{tabular}{|c|c|c|c|c|c|c|}
\hline Matching model & Sample & Mean Bias & Median bias & Pseudo- $R^{2}$ & $\operatorname{LR} x^{2}$ & $P>X^{2}$ \\
\hline \multirow[t]{2}{*}{ Any outpatient visit } & Unmatched & 22.2 & 15.8 & 0.125 & 276.16 & 0.000 \\
\hline & Matched & 3.9 & 3.1 & 0.005 & 5.97 & 0.918 \\
\hline \multirow[t]{3}{*}{ Outpatient institutions } & Unmatched & 24.4 & 17.6 & 0.173 & 68.82 & 0.000 \\
\hline & Matched & 7.9 & 7.6 & 0.027 & 7.24 & 0.841 \\
\hline & Matched & 10.2 & 7.5 & 0.036 & 9.29 & 0.751 \\
\hline \multirow[t]{2}{*}{ Any inpatient visit } & Unmatched & 21.1 & 17.7 & 0.092 & 506.15 & 0.000 \\
\hline & Matched & 3.0 & 2.7 & 0.002 & 5.46 & 0.859 \\
\hline \multirow[t]{3}{*}{ Inpatient institutions } & Unmatched & 17.2 & 13.4 & 0.073 & 96.95 & 0.000 \\
\hline & Matched & 3.0 & 3.4 & 0.003 & 2.01 & 0.996 \\
\hline & Matched & 5.2 & 4.4 & 0.011 & 7.94 & 0.719 \\
\hline
\end{tabular}


Table 3 The ATT of the PRP on health services utilization

\begin{tabular}{|c|c|c|c|c|c|c|}
\hline \multirow[t]{2}{*}{ Outcomes } & \multicolumn{2}{|c|}{ Means after matching } & \multicolumn{3}{|c|}{ Average treatment effects } & \multirow{2}{*}{$\begin{array}{l}\text { Number of cases } \\
\text { on support }\end{array}$} \\
\hline & Treatment & Control & ATT & SE & $P$-value & \\
\hline Any outpatient visit & 0.2206 & 0.2218 & -0.0012 & 0.0327 & 0.976 & 2352 \\
\hline Outpatient institutions & 2.092 & 2.107 & -0.015 & 0.161 & 0.945 & 466 \\
\hline Any inpatient visit & 0.2599 & 0.2084 & 0.0515 & 0.0192 & 0.026 & 5932 \\
\hline Inpatient institutions & 1.857 & 1.853 & 0.004 & 0.070 & 0.961 & 1183 \\
\hline
\end{tabular}

obtained several important findings. Our main finding revealed that the PRP has made some achievements in reducing inequality in health services utilization among the poor. Within one year of the survey, under the premise of consistent health services demand, the beneficiaries occurred more inpatient services utilization. However, no significant difference existed in outpatient services utilization between the treatment group and the control group. The inpatient visit rate within one year was approximately $5 \%$ higher for the treatment group than for the control group. These findings showed that the PRP mainly protects the poor with serious diseases from catastrophic health expenditures.

Most rural residents in China experience inequality in health services utilization owing to the income gap [19, 41]. Our study found that the PRP has alleviated this situation to a certain extent and has mainly improved the beneficiaries' access to inpatient services. It is worth noting that the beneficiaries of the PRP did not appear to make higher-level choices of health services institutions for inpatients, as $87.63 \%$ of the inpatients in the treatment group chose public hospitals at the county or township level. However, only $59.61 \%$ of the outpatients chose primary health services institutions (village clinics or town health centers) for treating diseases that occurred within two weeks of the survey, which is a large gap from China's goal of guiding patients to seek health services at primary health services institutions as well as one of the main goals of establishing a hierarchical diagnosis and treatment system in China [42, 43]. The hierarchical diagnosis and treatment system aims to promote the rational allocation of medical resources and promote equal access to basic health services by dividing health services institutions geographically into three different tiers in rural China: county hospitals, town health centers and village clinics [42, 44]. Four principles are suggested by the system to optimize health services provision: the initial diagnosis and treatment should be made by primary health services institutions; a bidirectional patient referral should be executed to provide optimal health services; acute and chronic diseases should be treated distinctively by the appropriate channels in health services institutions at different tiers; and medical resource optimization should be carried out within the three tiers rather than within an individual health services institution [42, 44].

The explanation of the supply side for the above results is that the main goal of the PRP in the health field is to guarantee basic health services and the treatment of serious diseases but not to provide excessive health services $[7,8]$; thus, the PRP does not encourage the beneficiaries to acquire a high level of health services to avoid moral hazard. Outpatient expenditures are usually small and unlikely to cause catastrophic health expenditures among the poor; thus, the PRP is not concerned about outpatient assistance.

On the demand side, Yan-Ning Li et al.'s survey in rural areas of Guangxi Zhuang Autonomous Region (Southwestern Province) showed that the most important factors affecting residents' two-week illness rate were need factors (such as illness) rather than economic factors [45]. After using PSM to eliminate the effects of disease characteristics and the HRQoL on residents' health services utilization, we also found that the PRP had no effects on residents' two-week outpatient visit rates. In addition, $\mathrm{Lu}$ Zhang et al.'s study in rural areas of Gansu Province (Northwestern Province) showed that increasing outpatient reimbursement rates had no effect on the choice of outpatient institution for type- 2 diabetes patients [46]. Only $28 \%$ of patients with type- 2 diabetes chose village clinics, and 33\% chose town health centers for health services [46]. The main reason is that Chinese residents' distrust in primary health services institutions was higher

Table 4 Sensitivity analysis for matching models

\begin{tabular}{lllll}
\hline$\Gamma$ & P-value & & \\
\cline { 2 - 5 } & Any outpatient visit & Outpatient institutions & Any inpatient visit & Inpatient institutions \\
\hline 1 & 0.455 & 0.433 & 0.101 & 0.639 \\
1.5 & 0.991 & 0.938 & 0.998 & 0.998 \\
2 & 1.000 & 0.997 & 1.000 & 1.000 \\
2.5 & 1.000 & 1.000 & 1.000 & 1.000 \\
3 & 1.000 & 1.000 & 1.000 & 1.000 \\
\hline
\end{tabular}


than their distrust in hospitals at the county level and above [47], and this high distrust of primary health institutions was strongly associated with increased hospital outpatient services utilization [47]. Some studies have shown that convenience is also an important factor that affects outpatient services utilization among Chinese residents $[45,48,49]$. In general, the impact of the PRP on outpatient services utilization among rural residents is minimal. Instead, residents' disease characteristics, health status, trust in health services institutions, and convenience are the main factors affecting outpatient services utilization.

Different from outpatient services utilization, many studies have shown that economic factors and need factors both play dominant roles in inpatient services utilization among Chinese residents [45, 48, 50]. Meanwhile, a Chinese nationally representative survey from 1993 to 2008 showed that with the same needs for health services, rich rural residents utilized more health services than poor rural residents, and inpatient services utilization was more inequitable [51]. Our study shows that after controlling for demographic socioeconomic characteristics and need factors (HRQoL), the PRP increased the inpatient visit rate of the beneficiaries by approximately 5 percentage points, indicating that MFA provided by the PRP greatly reduced the inequality of inpatient services utilization caused by the income gap.

In general, the PRP has achieved some goals to improve health services utilization for the beneficiaries, mainly by increasing their inpatient visit rate. Compared to the nonbeneficiaries, the beneficiaries were more willing and able to obtain inpatient services when they suffered from serious diseases because they were safeguarded by the PRP [18]. This finding indicates that the PRP has made progress in reducing inequality in the health services utilization of the rural poor, including the formulation and improvement of policies, the targeted identification of the poor and the increase and management of MFA funds [52]. Despite these achievements, further PRP improvements are needed.

The MFA strategies of the PRP have achieved good results in reducing the inequality of inpatient services utilization among the rural poor in China, indicating that these strategies should continue to be implemented. However, the PRP has not been able to improve the equality of the outpatient services utilization of the rural poor on the demand side, and government departments should improve the responsiveness of the supply side to meet the outpatient services needs of the rural poor. Specifically, the government should guide primary health services institutions to make greater efforts to improve the satisfaction of rural residents, with the aim of encouraging the rural poor to initially access diagnosis and treatment in primary health services institutions when needed. Primary health services institutions in rural
China generally have weak services capacity and poor medical quality, which is the main reason for the low satisfaction of rural residents in China [53, 54]. Therefore, improving the services capacity and medical quality of primary health services institutions will guide patients to choose primary health services institutions, which should be the core task of China's rural health policies [53-55]. The deployment and training of health technicians and general practitioners is the main measure to achieve this goal $[53,55,56]$, [57]. Through these efforts, the efficiency of primary health services institutions and the health outcomes of the rural poor will improve, and the financial risks of the rural poor due to catastrophic health expenditures will decrease.

\section{Limitations}

A few limitations exist in our study. First, we use crosssectional data to conduct the study, which cannot longitudinally observe the changes in health services utilization among the beneficiaries of the PRP in the early, middle and late stages of the benefits. Second, although we use quasi-experimental methods for the analysis, given the limited number of variables and the sample size, the matching models still contain bias, which reduces the accuracy of the results. In particular, due to the limitations of the survey, factors such as social culture, health literacy, and psychology are not included in the control variables, and these factors may have different degrees of effects on health services utilization among the rural poor. These limitations should be further addressed in future research.

\section{Conclusions}

Our study found that the PRP has to some extent reduced inequality in health services utilization among rural residents, which is caused by the income gap, mainly by increasing the beneficiaries' inpatient visit rate within one year. In addition, the vast majority of the beneficiaries choose inpatient institutions at the county or township level. These results show that the PRP plays a positive role in the beneficiaries' inpatient services utilization. However, the PRP had no effects on the two-week outpatient visit rate and choice of outpatient institution among the poor. Moreover, due to weak services capacity and poor medical quality, a considerable number of the beneficiaries failed to initially access health services at primary health services institutions after they became ill. The limited role of the PRP in outpatient services leads to disordered treatment and insufficient reduction of medical burden among the poor. Policy makers need to pay attention to improving the responsiveness of the primary health services system and guiding patients to initially access health services in primary health services institutions by improving the services capacity and medical quality of primary health services institutions. 


\section{Appendix}

Table $\mathbf{5}$ The distribution of diseases classification for beneficiaries and non-beneficiaries

\begin{tabular}{|c|c|c|c|c|c|c|}
\hline \multirow[t]{2}{*}{ Diseases Classification } & \multicolumn{3}{|c|}{ Number of outpatients } & \multicolumn{3}{|c|}{ Number of inpatients } \\
\hline & Beneficiaries & Non-beneficiaries & Total & Beneficiaries & Non-beneficiaries & Total \\
\hline Certain infectious and parasitic diseases & 9 & 14 & 23 & 5 & 9 & 14 \\
\hline Neoplasms & 17 & 28 & 45 & 11 & 39 & 50 \\
\hline $\begin{array}{l}\text { Diseases of the blood and blood-forming organs and certain } \\
\text { disorders involving the immune mechanism }\end{array}$ & 3 & 4 & 7 & 3 & 4 & 7 \\
\hline Endocrine, nutritional and metabolic diseases & 26 & 182 & 208 & 11 & 37 & 48 \\
\hline Mental and behavioural disorders & 13 & 10 & 23 & 7 & 10 & 17 \\
\hline Diseases of the nervous system & 13 & 40 & 53 & 8 & 21 & 29 \\
\hline Diseases of the eye and adnexa & 8 & 25 & 33 & 6 & 28 & 34 \\
\hline Diseases of the ear and mastoid process & 2 & 10 & 12 & 2 & 5 & 7 \\
\hline Diseases of the circulatory system & 82 & 597 & 679 & 52 & 187 & 239 \\
\hline Diseases of the respiratory system & 64 & 245 & 309 & 49 & 146 & 195 \\
\hline Diseases of the digestive system & 29 & 139 & 168 & 24 & 95 & 119 \\
\hline Diseases of the skin and subcutaneous tissue & 2 & 18 & 20 & 2 & 5 & 7 \\
\hline Diseases of the musculoskeletal system and connective tissue & 80 & 409 & 489 & 36 & 97 & 133 \\
\hline Diseases of the genitourinary system & 27 & 98 & 125 & 19 & 93 & 112 \\
\hline Pregnancy, childbirth and the puerperium & 0 & 1 & 1 & 4 & 39 & 43 \\
\hline Certain conditions originating in the perinatal period & 0 & 1 & 1 & 0 & 1 & 1 \\
\hline $\begin{array}{l}\text { Congenital malformations, deformations and chromosomal } \\
\text { abnormalities }\end{array}$ & 3 & 3 & 6 & 0 & 1 & 1 \\
\hline $\begin{array}{l}\text { Symptoms, signs and abnormal clinical and laboratory findings, } \\
\text { not elsewhere classified }\end{array}$ & 25 & 85 & 110 & 23 & 30 & 53 \\
\hline Injury, poisoning and certain other consequences of external causes & 27 & 95 & 122 & 30 & 125 & 155 \\
\hline
\end{tabular}

Note:The diseases classification is based on the ICD-10 released by the WHO

\section{Abbreviations}

ATT: Average treatment effects on the treated; Dibao: Minimum livelihood guarantee program; HRQOL: Health-related quality of life; NCMS: New Cooperative Medical Scheme; OOP: Out-of-pocket; PRP: Poverty reduction policy; PSM: Propensity score matching; SES: Socioeconomic status; TPA: Targeted poverty alleviation; Wubao: Poverty-stricken population support program

\section{Acknowledgments}

We thank all of the officers and medical staff involved in this study. In addition, we could not have finished this study without their generous assistance.

\section{Authors' contributions}

QZ, LZ and XQH drafted the outline of this study. All coauthors were responsible for collecting the data. ZL performed the data management. QZ performed the data analysis. All coauthors critically reviewed the first results. QZ drafted the first manuscript, and $L Z, X Q H, Z L$, and WCX gave critical feedback. All authors read and approved the final manuscript.

\section{Funding}

This work was funded by the National Natural Science Foundation of China (Grant NO: 71734003). The funder had no role in the design of the study; the collection, analysis, and interpretation of data; or the writing of the manuscript.

\section{Availability of data and materials}

The datasets used and analyzed during the current study are available from the corresponding author on reasonable request.
Ethics approval and consent to participate

The study was approved by the ethics committee of Tongji Medical College, Huazhong University of Science and Technology (IORG No: IORG0003571). Informed consent was obtained from the participants enrolled in the household survey, and the respondents were assured that their participation was voluntary and that they could withdraw from the study at any time.

\section{Consent for publication}

Not applicable

\section{Competing interests}

The authors declare that they have no competing interests

Received: 18 August 2019 Accepted: 18 November 2019

Published online: 29 November 2019

\section{References}

1. People's daily: Xi Jinping's speech at the celebration of the 40th anniversary of reform and opening up. http://cpc.people.com.cn/n1/2018/1219/c64 094-30474974.html (2018) Accessed 3 March 2019.

2. United Nations: The sustainable development goals report. 2018.

3. National Bureau of Statistics of China: China Statistical Yearbook 2018; 2018.

4. Lu Y, Zhang Y, Cao X, Wang C, Wang Y, Zhang M, Ferrier RC, Jenkins A, Yuan J, Bailey MJ, et al. Forty years of reform and opening up: China's progress toward a sustainable path. Sci Adv. 2019;5(8):u9413.

5. China Pictorial: Precision Poverty Relief: China's New Anti-Poverty Strategy. http://www.chinapictorial.com.cn/en/features/txt/2016-03/02/content_7145 04_3.htm (2016) Accessed 5 March 2019.

6. China National State Council: Decision of the Central Committee of the Communist Party of China and the State Council on winning the fight 
against poverty. http://www.gov.cn/xinwen/2015-12/07/content_5020963. htm (2015) Accessed 5 March 2019.

7. China National State Council: Guidance on the implementation of health poverty alleviation projects. http://www.gov.cn/xinwen/2016-06/21/ content_5084195.htm (2016) Accessed 12 November 2018.

8. China National State Council: Interim Measures for Social Interim Measures for Social Assistance. http://www.gov.cn/zhengce/2014-02/28/ content_2625652.htm (2015) Accessed 5 March 2019.

9. Golan J, Sicular T, Umapathi N. Unconditional cash transfers in China: who benefits from the rural minimum living standard guarantee (Dibao) program? World Dev. 2017;93:316-36.

10. China National State Council: Rural Five Guarantees Regulations. http://www.gov.cn/zhengce/content/2008-03/28/content_6253.htm (2008) Accessed 5 October 2019.

11. Guo Y, Zhou Y, Liu Y. Targeted poverty alleviation and its practices in rural China: a case study of Fuping county. Hebei Province J RURAL STUD. 2019

12. Zhao L, Guo Y, Shao T. Can the minimum living standard guarantee scheme enable the poor to escape the poverty trap in rural China? Int I Soc Welf. 2017;26(4):314-28

13. Yansui Liu YZJL. Regional differentiation characteristics of rural poverty in China and targeted poverty alleviation strategies. J Chinese Academy Sci. 2016;31(3):269-78.

14. Xie E. Income-related inequalities of health and health care utilization. Frontiers of Economics in China. 2011;6(1):131-56.

15. Meghea Cl, Raffo JE, Zhu Q, Roman L. Medicaid home visitation and maternal and infant healthcare utilization. Am J Prev Med. 2013;45(4):441-7.

16. Peters DH, Garg A, Bloom G, Walker DG, Brieger WR, Hafizur Rahman M. Poverty and access to health Care in Developing Countries. Ann N Y Acad Sci. 2008;1136(1):161-71.

17. Makinen M, Waters $H$, Rauch M, Almagambetova N, Bitran R, Gilson L, McIntyre D, Pannarunothai S, Prieto AL, Ubilla G, et al. Inequalities in health care use and expenditures: empirical data from eight developing countries and countries in transition. Bull World Health Organ. 2000;78(1):55-65.

18. Zhou Z, Gao J, Fox A, Rao K, Xu K, Xu L, Zhang Y. Measuring the equity of inpatient utilization in Chinese rural areas. BMC Health Serv Res. 2011;11:201.

19. Zhou Z, Fang Y, Zhou Z, Li D, Wang D, Li Y. Assessing income-related health inequality and horizontal inequity in China. Soc Indic Res. 2017;132(1):241-56.

20. China National Health Commission: Notice on the Establishment of New Rural Cooperative Medical System. http://www.nhc.gov.cn/jws/s6476/200804/ 9cd8965c238c4d1ca52b2cf4f8274b23.shtml (2007) Accessed 5 March 2019.

21. China National Health Commission: China health statistical yearbook 2017. 2017.

22. Chen J, Dong H, Yu H, Gu Y, Zhang T. Impact of new rural cooperative medical scheme on the equity of health services in rural China. BMC Health Serv Res. 2018;18:486.

23. Li C, Hou Y, Sun M, Lu J, Wang Y, Li X, Chang F, Hao M. An evaluation of China's new rural cooperative medical system: achievements and inadequacies from policy goals. BMC Public Health. 2015;15:1079.

24. Guo N, Iversen T, Lu M, Wang J, Shi L. Does the new cooperative medical scheme reduce inequality in catastrophic health expenditure in rural China? BMC Health Serv Res. 2016;16:653.

25. Ma J, Xu J, Zhang Z, Wang J. New cooperative medical scheme decreased financial burden but expanded the gap of income-related inequity: evidence from three provinces in rural China. Int J Equity Health. 2016;15:72. 2016;15(1).

26. Qun Meng LXYZ. Trends in access to health services and financial protection in China between 2003 and 2011: a cross-sectional study. LANCET. 2012;379:805-14.

27. Shi W, Chongsuvivatwong V, Geater A, Zhang J, Zhang H, Brombal D. The influence of the rural health security schemes on health utilization and household impoverishment in rural China: data from a household survey of western and Central China. Int J Equity Health. 2010;9:7.

28. Sun X, Sleigh AC, Carmichael GA, Jackson S. Health payment-induced poverty under China's new cooperative medical scheme in rural Shandong. Health Policy Plann. 2010;25(5):419-26.

29. Wang L, Wang A, FitzGerald G, Si L, Jiang Q, Ye D. Who benefited from the New Rural Cooperative Medical System in China? A case study on Anhui Province. BMC Health Serv Res. 2016;16:195.

30. Liu K, Yang J, Lu C. Is the medical financial assistance program an effective supplement to social health insurance for low-income households in China? A cross-sectional study. INT J EQUITY HEALTH. 2017;16:138.
31. Chen C, Pan J. The effect of the health poverty alleviation project on financial risk protection for rural residents: evidence from Chishui City, China. Int J Equity Health. 2019;18:79

32. Lagarde $\mathrm{M}$, Haines $\mathrm{A}$, Palmer $\mathrm{N}$. The impact of conditional cash transfers on health outcomes and use of health services in low and middle income countries. Cochrane DB Syst Rev. 2009. https://doi.org/10.1002/14651858. CD008137.

33. Shahidi FV, Ramraj C, Sod-Erdene O, Hildebrand V, Siddiqi A. The impact of social assistance programs on population health: a systematic review of research in high-income countries. BMC Public Health. 2019;19:2.

34. Yao Q, Liu C, Zhang Y, Xu L. Health-related quality of life of people with self-reported hypertension: a National Cross-Sectional Survey in China. Int J Env Res Pub He. 2019;16(10):1721.

35. Liu GG, Wu H, Li M, Gao C, Luo N. Chinese time trade-off values for EQ-5D health states. Value Health. 2014;17(5):597-604.

36. WHO: International Statistical Classification of Diseases and Related Health Problems 10th Revision (ICD-10)-WHO Version for 2016. https://icd.who.int/ browse10/2016/en (2016)Accessed 5 May 2019.

37. Rubin DB. Estimating causal effects from large data sets using propensity scores. Ann Intern Med. 1997;127(8 Pt 2):757-63.

38. Paul PR. The central role of the propensity score in observational studies for causal effects. Biometrika. 1983;70(1):41-5.

39. Paul PR. Observational studies. New York: Springer New York; 2002.

40. Keele L: An overview of rbounds: an R package for Rosenbaum bounds sensitivity analysis with matched data. White Paper 2010:1-15.

41. Zhou Z, Su Y, Gao J, Campbell B, Zhu Z, Xu L, Zhang Y. Assessing equity of healthcare utilization in rural China: results from nationally representative surveys from 1993 to 2008. Int J Equity Health. 2013;12:34.

42. China National State Council: Guidance on promoting the construction of hierarchical diagnosis and treatment system. http://www.gov.cn/zhengce/content/2015-09/11/content_10158.htm (2015) Accessed 5 May 2019.

43. Chen Z. Launch of the health-care reform plan in China. Lancet. 2009; 373(9672):1322-4.

44. Liu K, Zhang R, Yin L, Sun L, Pan X, Hou L, Shang X, Yang X. Medical service unity: an effective approach for medical care in rural areas in China. Rural Remote Health. 2018;18(3)

45. Li Y, Nong D, Wei B, Feng Q, Luo $\mathrm{H}$. The impact of predisposing, enabling, and need factors in utilization of health services among rural residents in Guangxi, China. BMC Health Serv Res. 2016;16(1).

46. Zhang L, Wang Z, Qian D, Ni J. Effects of changes in health insurance reimbursement level on outpatient service utilization of rural diabetics: evidence from Jiangsu Province. China BMC Health Serv Res. 2014;14:185.

47. Duckett J, Hunt K, Munro N, Sutton M. Does distrust in providers affect health-care utilization in China? Health Policy Plann. 2016;31(8): 1001-9.

48. Zhang X, Wu Q, Shao Y, Fu W, Liu G, Coyte PC. Socioeconomic inequities in health care utilization in China. Asia Pacific J Pub Health. 2015;27(4):429-38.

49. Liu G, Xue Y, Qian Z, Yang L, Yang Y, Geng Q, Wang X. Healthcare-seeking behavior among pregnant women in the Chinese hierarchical medical system: a cross-sectional study. INT J EQUITY HEALTH. 2019;18:129.

50. Qian Y, Zhou Z, Yan JE, Gao J, Wang Y, Yang X, Xu Y, Li Y: An economy-related equity analysis of health service utilization by women in economically underdeveloped regions of western China. Int J Equity Health. 2017;16:186

51. Zhou Z, Su Y, Gao J, Campbell B, Zhu Z, Xu L, Zhang Y. Assessing equity of healthcare utilization in rural China: results from nationally representative surveys from 1993 to 2008. Int J Equity Health. 2013;12:34.

52. He X, Li L, Bian Y. Satisfaction survey among primary health care outpatients in the backward region: an empirical study from rural Western China. Volume. 2018;12:1989-96.

53. Qian D, Pong RW, Yin A, Nagarajan KV, Meng Q. Determinants of health care demand in poor, rural China: the case of Gansu Province. Health Policy Plann. 2009;24(5):324-34

54. Li X, Lu J, Hu S, Cheng KK, De Maeseneer J, Meng Q, Mossialos E, U DR, yip W, Zhang $\mathrm{H}$ et al: The primary health-care system in china. LANCET 2017, 10112(390):2584-2594. 
55. Wu D, Lam TP, Lam KF, Zhou XD, Sun KS: Health reforms in china: the public's choices for first-contact care in urban areas. Fam Pract 2017: w133.

56. Bazemore A, Petterson S, Peterson LE, Phillips RL. More comprehensive care among family physicians is associated with lower costs and fewer hospitalizations. Ann Fam Med. 2015;3(13):206-13.

\section{Publisher's Note}

Springer Nature remains neutral with regard to jurisdictional claims in published maps and institutional affiliations.

Ready to submit your research? Choose BMC and benefit from:

- fast, convenient online submission

- thorough peer review by experienced researchers in your field

- rapid publication on acceptance

- support for research data, including large and complex data types

- gold Open Access which fosters wider collaboration and increased citations

- maximum visibility for your research: over $100 \mathrm{M}$ website views per year

At BMC, research is always in progress.

Learn more biomedcentral.com/submissions 